\title{
Launching a Cross-disciplinary and Cross-national Conversation on Engaged Fatherhood
}

\author{
Marc Grau Grau and Hannah Riley Bowles
}

\section{Origins}

This edited volume stems from a multi-disciplinary Experts Meeting on Fatherhood Engagement hosted by the Harvard Kennedy School's Women and Public Policy Program, funded by the Social Trends Institute (STI), and organized in collaboration with the International Center for Work and Family at the Instituto de Estudios Superiores de la Empresa (IESE) Business School. We invited experts from the healthcare, social policy, and work and organization fields because those are the professional fields that have done the most to advance scholarship and practice in relation to fatherhood engagement. The participants arrived at the meeting, not only with distinct disciplinary perspectives, but also with complementary motivations for elevating the importance of fatherhood engagement. Some arrived focused primarily on enhancing the welfare of men. Others were drawn by the importance of fatherhood engagement for the health and welfare of families and for child development. Still others joined for a conversation about work-family balance or to promote gender equality. As the meeting progressed, it was inspiring to see scholars and institutions with diverse worldviews come together so enthusiastically to support a common aim: elevating the importance of fatherhood engagement. This book is a reflection of the kaleidoscopic character of these conversations.

\footnotetext{
M. Grau Grau ( $₫)$

Women and Public Policy Program, Harvard Kennedy School, Cambridge, MA, USA

Joaquim Molins Figueras Childcare and Family Policies Chair, Universitat Internacional de Catalunya, Barcelona, Spain

e-mail: marc_grau-grau@hks.harvard.edu

H. Riley Bowles

Women and Public Policy Program, Harvard Kennedy School, Cambridge, MA, USA
} 


\section{Why Focus on Fathers?}

What is urgent or important about a conversation on fathers? Men, and especially working fathers, are arguably a privileged group in a world of inequality. Don't they "have it all" at home and at work? We had two driving motivations to pursue this work. First, over the past 30 years, scholars in the medical sciences, child development, and social policy have gathered an accelerating amount of evidence on the value and importance of engaged fatherhood for the health and welfare of children and families, and for men themselves. Numerous contributors to this volume have been at the leading edge of this work and are capturing growing attention. The second motivation was to elevate the importance of fatherhood engagement for the advancement of gender equality, a topic often sidelined by emphasis on increasing women's occupational attainment.

\subsection{Mounting Evidence}

As elaborated in the leading chapters by Yogman and Eppel and by Kotelchuck in the Health and Wellbeing section of the book, the importance of engaged fatherhood is now undismissable in ways it was not in earlier decades. A growing body of evidence demonstrates the importance of residential and non-residential fathers on families' welfare and economic wellbeing; on mothers' prenatal health and birth outcomes; on children's cognitive, psychosocial, and educational development and gender identity; and on adolescent behavioral risk reduction among other benefits (Alio et al. 2010; Cano et al. 2019; Yogman et al. 2016). Of particular significance to the development of fatherhood research has been the emergence of national and cross-national longitudinal studies on children and families that explore the contributions of fathers (e.g., Huerta et al. 2013; Nepomnyaschy and Waldfogel 2007; Petts et al. 2020). These social scientific studies have blossomed alongside a proliferation of medical scientific studies on the importance engaged parenting (National Academies of Sciences, Engineering and Medicine et al. 2016; Yogman et al. 2016).

Moreover, as discussed in the chapter on "The Impact of Fatherhood on Men's Health and Development" by Kotelchuck, the benefits of fatherhood involvement are not limited to children's and mothers' wellbeing; there is growing evidence documenting the benefits of fatherhood involvement for men themselves (Eggebeen et al. 2010; Eggebeen and Knoester 2001), ranging from better psychological and physical health outcomes to the development of new capacities as employees (GrauGrau 2017). There are also significant strains of fatherhood for men that need to be addressed for the welfare of men and their families (Cameron et al. 2016).

In sum, it is no longer possible for evidence-based decision makers-clinicians, policy makers, or other family service providers-to responsibly ignore the 
significance of engaged fatherhood for the welfare of families and children and for men themselves.

\subsection{Gender Equality}

Another reason to elevate the importance of engaged fatherhood is to give a push forward to the revolution for gender equality - a movement that is widely perceived to have stalled (England 2010; Esping-Andersen 2009; Gerson 2010). As Goldscheider et al. (2015) have argued, the first half of the revolution toward gender equality has been focused on increasing women's participation in the public realm of paid labor. Completing the revolution will require increasing men's participation in the private realm of familial caregiving.

Women's growing participation in paid labor has been a primary factor in transforming social conceptions of fathers as "caregivers" as well as "breadwinners" (Lewis 2001). The leading chapters to the Social Policy section of the book by Koslowski and O'Brien and by Kvande provide a historical perspective on how social policies designed to support women's workforce participation and the economic welfare of families have contributed to rising rates of participation in early fatherhood.

As illustrated in Fig. 1, fathers across the globe have become more engaged in their children's lives as compared to 50 years ago. The chart plots the percentage of fathers spending at least 15 min on childcare each day, as reported by Altintas and

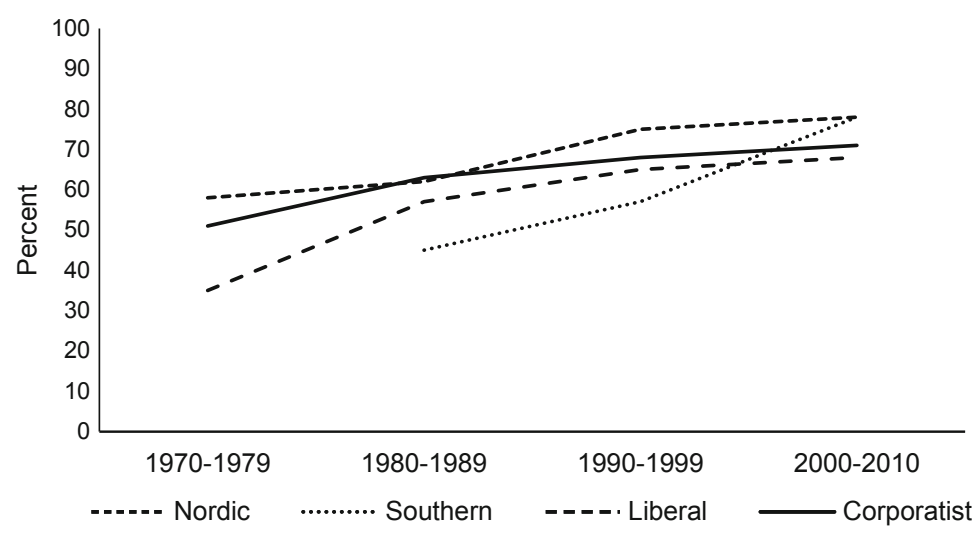

Fig. 1 Percentage of fathers spending at least 15 min on childcare each Day (1970-2010). (Source: Data reported by Altintas and Sullivan (2017; see Table 1, pg. 92) from the Multinational Time Use Study). Note: Fathers are men 20-49 years of age who are married/cohabiting and living with at least one child under the age of 5. Nordic cluster countries are Denmark, Finland, Norway and Sweden. Southern cluster countries are Italy, Spain and Israel. Liberal cluster countries are Canada, the United Kingdom, the United States and Australia. Corporatist cluster countries are France, Germany, the Netherlands and Slovenia 


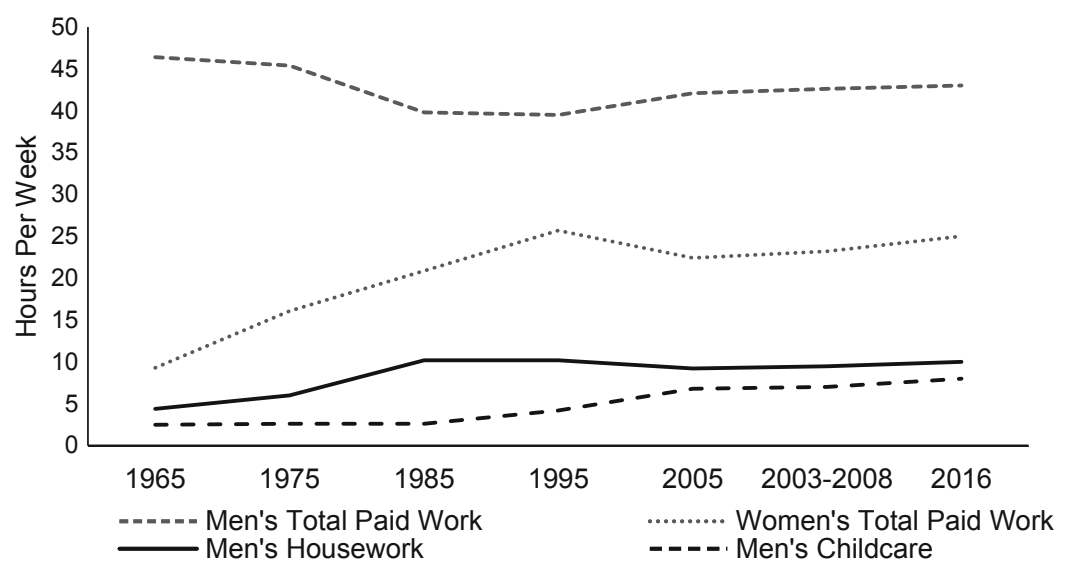

Fig. 2 Time use of mothers and fathers in the United States (hours per week) (1965-2016). (Source: Data for years 1965-2008 were reported by Bianchi [2011; see Tables 1-2, pages 27 and 29, respectively]). Data for 2016 were reported by Livingston and Parker (2019) of the Pew Research Center. Note: Age of sample is 18-64 years

Sullivan (2017) in their analysis of Multinational Time Use Survey data (1971-2010) from 15 countries. As illustrated, the Nordic countries (i.e., Denmark, Finland, Norway, Sweden) started out and surged farther ahead of other regions in the 1990s, but are now simply on par with time-use reports from the Southern region (i.e., Israel, Italy, Spain). The percentage growth in "Liberal" English-speaking (i.e., Australia, Canada, U.K., U.S.) and "Corporatist" European (i.e., France, Germany, Netherlands, Slovenia) has stagnated, but has risen from a minority to a majority of fathers.

The spreading duality of fathers (and mothers) as caregivers and breadwinners has generated new conflicts and tensions for men, especially at work. As discussed in the leading chapter of the section on Work and Organizations by Ladge and Humberd, men are experiencing increasing levels of work-family conflict. One report from United States found that the proportions of working fathers reporting work-family conflict jumped from $35 \%$ in 1977 to $60 \%$ in 2008 , while for mothers the percentage experiencing work-family conflict remained more stable $(41 \%$ in 1977 and 47\% in 2008) (Aumann et al. 2011). Other studies report similar findings that men's sense of work-family conflict is beginning to rival or surpass women's (Eagle et al. 1997; Parasuraman and Simmers 2001), especially among fathers in dual-career couples (Higgins and Duxbury 1992). As discussed by Ladge and Humberd, one explanation for this growing work-family tension for men relative to women is that gender roles around parenting are evolving at a faster pace than employers' masculine stereotypic conception of the "ideal worker" who has no conflicting familial or household obligations (Acker 1990).

While the gendered division of household labor is undoubtedly evolving, there are signs that the rate of change in many places is stalling. Figure 2 is illustrative. It displays 50 years of data from time-use surveys of U.S. mothers and fathers of 
children under 18 (Bianchi 2011; Livingston and Parker 2019). The marked gains in women's labor-market participation and men's contributions to childcare and household labor between 1965 and 2005 have since largely flattened out. Despite devoting more time to their children than previous generations, fathers are still not typically the primary caregiver "on call" to deal with the vicissitudes of family life (e.g., being available at short notice for the care of sick children), leaving working mothers as the primary consumers of family-friendly social and work policies (Goldin and Mitchell 2017; Kelly et al. 2010; Mandel and Semyonov 2005). The final Work and Organization chapters of the book explore how cultural conceptions of masculinity and of fatherhood, as well as variations in the culture of work, constrain men's capacity to integrate their breadwinning and caregiving roles and identities.

\subsection{Increasing Fatherhood Engagement Is a Win-Win Proposition}

The participants in the Experts Meeting and contributors to this volume approach the challenge of fatherhood engagement from a "win-win" rather than zero-sum perspective. The larger objective of this volume is not to "win more" for fathers, but rather to reap the mutual gains from engaged fatherhood for families, children, and men themselves and, in the process, to advance the ideals of gender equality. In the concluding chapter, Bowles, Kotelchuck, and Grau Grau propose a set of working principles for reducing the barriers to fatherhood engagement, which were generated from this collaboration to apply across the social policy, work, and healthcare systems.

\section{Fostering Cross-disciplinary Learning and Coordination}

The Experts Meeting and this volume have enabled an unprecedented flow of ideas across burgeoning, but largely separate, streams of work. At the meeting, top health experts, social policy scholars, and organizational scientists from around the globe presented and discussed research on the antecedents and implications of men's engagement in fatherhood. It was an extraordinary learning opportunity, even for those who had been in the field for decades. It was particularly eye-opening to recognize the differential and common struggles across these three fields and across national cultural contexts. This volume was motivated by our enthusiasm to share our exchange of ideas and insights.

Reflecting the contributions to the Experts Meeting, the book is organized in three sections: Health and Welfare, Social Policy, and Work and Organizations. Across the sections, the chapters review evidence and case examples from more than 20 different countries representing 6 global regions. Each chapter is intentionally 
crafted to speak to mixed audiences in order to be useful to scholars and practitioners in different fields, as well as to families and loved ones supporting fathers and mothers in parenting roles.

\subsection{Health and Wellbeing}

The first section of the book is dedicated to voices of medical scholars discussing the implications of early fatherhood involvement for the health and development of children, parenting partners, and men themselves. It offers strategies for healthcare providers to support men more directly and effectively as prospective and current fathers. In spite of the growing evidence, the health community struggles to increase recognition of fathers' roles and contributions in the care of infants and children in a sector traditionally focused on the mothers as parents. Fathers currently interact with healthcare systems, albeit to a lesser extent than mothers, during the antenatal period, the birth of the child, and after the birth. However, fathers commonly feel as if they are "secondary parents" in these healthcare interactions (Steen et al. 2012).

The contributors to the Health and Wellbeing section advocate for engaging fathers preceding infants' conception through reproductive health and birthing services into the pediatricians' offices in order to enhance infant, maternal, and men's own health. They emphasize that failure to do so reinforces traditional cultural expectations of fathers rather than leading the charge for gender role changes. It also fails to recognize that the perinatal period is a demanding developmental period for fathers, who too experience important physical, psychological, and social changes.

In the chapter on "The Role of Fathers in Child and Family Health", Yogman and Eppel present the impact of fatherhood across four stages of childhood: prenatal, infancy, childhood, and adolescence. Their review advocates for policies enhancing father involvement, accessible and more extensive paternity leave, and increased attention to paternal postpartum depression by the medical community. In his chapter on "The Impact of Father's Health on Reproductive and Infant Health and Development", Kotelchuck articulates eight direct and indirect pathways by which fathers' perinatal health and health-related behavior impact reproductive and infant health. His review organizes a heretofore scattered scientific knowledge base and pulls back the developmental time frame for fathers' reproductive health importance into the antenatal pre-birth period. In his second chapter on "The Impact of Fatherhood on Men's Health and Development", which is deeply interrelated with his prior chapter on "The Impact of Father's Health on Reproductive and Infant Health and Development", Kotelchuck explores the bidirectional life-course impact of fatherhood on men's physical, mental, social and developmental health in the perinatal period. This represents a new focus for the Maternal Child Health (MCH) field, especially in the perinatal time period, a time not usually thought of as impacting men's health. In their chapter on "Steps in Developing a Public Health Surveillance System for Fathers", Simon and Garfield describe efforts to establish a new public health surveillance system for fathers in the United States. The ultimate goal of this 
research is to collect and assess fathers' health and parenting experiences in the perinatal period, in order to support the development of effective perinatal clinical and public health practices, programs, and policies to improve the health and development of infants, mothers, and fathers.

Finally, in their chapter on "Fatherhood and Reproductive Health in the Antenatal Period: From Men's Voices to Clinical Practice", Levy and Kotelchuck present the results of the first Massachusetts General Hospital Fatherhood Prenatal Care Survey. This survey is path breaking as there is very limited literature on the experiences of fathers during Obstetric prenatal care, especially that directly includes fathers' voices. They find that fathers who have responded to the survey are actively and deeply engaged with the impending birth; have substantial physical and health needs including lack of primary care, depressive symptoms, and personal isolation; and have a strong desire for greater involvement in reproductive health care services. In conclusion, they make multiple practical recommendations to create a more fatherfriendly environment in Obstetric care.

\subsection{Social Policy}

At the meeting, social policy experts on family leave presented cross-national comparative studies of the implications of social policy, national culture, and socio-economic conditions on men's involvement in infant and childcare. A central struggle they discussed is how to motivate more gender equitable familial caretaking and economic outcomes.

There are multiple ways in which social policies can foster fatherhood involvement (Hearn et al. 2018). Parenting-related leaves, the set of social policies most analyzed in this book, are perhaps the most examined reproductive health policies in the literature. A key finding from this literature is that the initial transition from "mother-specific" to more general "parenting-related" leave policies enabled the inclusion of men, but had little practical effects because mothers continued to be the primary users (Bueno and Grau-Grau 2021; Moran and Koslowski 2019). In order to encourage men's participation in parenting-related leave policies, some countries, especially in Nordic Europe, offered father-specific leaves (e.g., "daddy quotas"). Evidence now shows that father-specific quotas tend to have significantly more positive effects relative to the use of gender-neutral parental leave (Mayer and Le Bourdais 2019), particularly in terms of increased paternal involvement with childcare over time (Bünning 2015) and increased solo parenting time (Wray 2020).

In their chapter on "Fathers and Family Leave Policies: What Public Policy Can Do to Support Families", Koslowski and O'Brien provide an overview of specific design features of family leave policies that tend to influence fathers' utilization, and they discuss documented effects of fathers' leaving taking on families' welfare and gender equality. In her chapter on "Individual Parental Leave for Fathers: Promoting Gender Equality in Norway", Kvande takes as a point of departure the design elements of the Norwegian parental leave system for fathers and examines how it 
works as a regulatory measure to promote equality in care work. The chapter on "How Do Men Talk About Taking Parental Leave? Evidence from South Korea, Spain, and the U.S." by Bueno and Oh enriches these first two chapters with more cross-national comparative perspectives. They present qualitative data on how men in South Korea, Spain, and the U.S. perceive parental leave, and comparatively analyze the fathers' perspectives as a function of their distinctive national cultural, social policy, and labor market contexts.

\subsection{Work and Organizations}

The Work and Organizations section provides further cross-national perspectives on fathers' experiences striving to fulfill work roles and family responsibilities. The grand challenge of this sector is how to practically operationalize a father-friendly work environment that is economically viable for both the family and the work organization.

The workplace is the environment where cultural and organizational norms and prejudices most clearly limit or enhance fathers' child-care and in-home family engagement. Many organizational cultures make engaged parenthood difficult. Even when organizations offer policies designed to reduce work-family conflicts, such as paid family leave and flexible work arrangements, they are commonly underutilized, particularly by fathers. Evidence suggests this is largely because being a person with limited family obligations tends to project a better work image than being one with a rich family life but obligations that could distract from the centrality of paid employment (Acker 1990; Tanquerel and Grau-Grau 2020; Williams et al. 2013).

In the chapter on "Impossible Standards and Unlikely Trade-Offs: Can Fathers Be Competent Parents and Professionals?", Ladge and Humberd set the stage for the Work and Organizations chapters by reflecting on contemporary challenges for working fathers and related unanswered questions in work and family research. In the chapter on "The New Dad: The Career-Caregiving Conundrum", Harrington reports on findings from a series of trailblazing studies conducted by the Boston College Center for Work \& Families, in which they surveyed working fathers about their transition to fatherhood and about their attitudes toward paternity leave, caregiving, and work-family balance. In the chapter on "French Fathers in Work Organizations: Navigating Work-Life Balance Challenges", Tanquerel presents an insightful comparative perspective on how French professional and working-class fathers address tensions between their work and familial roles. In the chapter on " It Would Be Silly to Stop Now and Go Part-Time': Fathers and Flexible Working Arrangements in Australia", Borgkvist examines how social constructions of masculinity in Australia sharpen the dissonance between men's identities as fathers and workers and how these incongruities inhibit men from utilizing family-friendly policies. In the chapter on "Small Changes That Make a Great Difference: Reading, Playing and Eating with Your Children and the Facilitating Role of Managers in 
Latin America", Bosch and Las Heras delve into a rich sample of data collected from working parents in seven Latin American countries. They analyze how organizations, through their managers, can promote positive fatherhood engagement, as measured by their participation in reading, playing and eating together with their children. In the chapter on "Fatherhood Among Marginalised Work-Seeking Men in South Africa", Malinga and Ratele illuminate ways in which men's precarious employment hinders the fatherhood engagement of day laborers in South Africa. Lacking the ability to provide financially for their families, the fathers are impeded from being physically present and showing their children love. In the final chapter on "The Role of Love and Children's Agency in Improving Fathers' Wellbeing", Macht closes the narrative circle of the contributors' chapters by returning to the theme of father-child wellbeing. Through her inductive exploration of data from interviews with fathers in Scotland and Romania, Macht proposes ways in which fathers are emotionally transformed and uplifted through loving relationships with their children, including by re-energizing them for work and helping them let go of negative health habits.

\section{Conclusion}

In the concluding chapter of the book, Bowles, Kotelchuck, and Grau Grau integrate insights gained from the Experts Meeting and from editing the chapters to propose a set of working principles for overcoming barriers to engaged fatherhood through social policy, work practices, and healthcare delivery. The motivations for this concluding chapter are twofold: first, to propose a preliminary framework to align efforts across the three sectors to support fatherhood engagement; and, second, to offer a rough conceptual foundation upon which to advance and broaden crossdisciplinary, cross-national collaboration.

Acknowledgements This volume would not have been possible without the collective and concerted efforts of numerous people and multiple institutions. First, we wish to express our absolute thankfulness to the Social Trends Institute (STI), who generously funded the Experts meeting, which was the inception of this book. Without STI, this journey would not have started. We are especially grateful to Carlos Cavallé, the President of STI, and Tracey O'Donnell, the Secretary General of STI, for their guidance and for trusting in this idea from the very beginning. We have enormous gratitude for their support in opening the access of this book to all readers.

We would like to express especial thanks to the Harvard Kennedy School's Women and Public Policy Program (WAPPP) for enabling our partnership, the vision for which Marc Grau Grau crafted as a post-doctoral Research Fellow. As WAPPP's co-director, Hannah Riley Bowles transformed this vision into a vivid event by hosting our Experts Meeting on the Harvard Kennedy School campus and has also co-crafted this volume. Among the warmly supportive and generously helpful WAPPP staff, we owe extra thanks to Nicole Carter Quinn, Lindsey Shepardson, and Ruth Hampton Reyes plus three interns who served as notetakers during the Experts Meeting: Raiya Al-Nsour, Tamar Harrison, and Grace Hoffer Gittell. We would also like to recognize WAPPP Research Fellow Logan Berg's instrumental assistance with our literature reviews, especially her careful eye for clarity and precision. Logan's contributions were made possible by the Lara Warner 
Scholars Fund, which supports WAPPP's mission to empower leaders and change makers with evidence-based strategies to advance gender equity.

As we worked to bring our aspirations for a cross-disciplinary dialogue to fruition, Mireia Las Heras was an early and enthusiastic partner and the linchpin in forming our institutional partnerships with IESE's International Center for Work and Family and STI. We are grateful for the cheerful assistance of Gemma Palet, Manager of the International Center for Work and Family, in the planning of the meeting.

Mireia Las Heras also served on our Steering Committee for the Experts Meeting representing the Work and Organizations section, along with Alison Koslowski from the University of Edinburgh and the International Network on Leave Policies and Research representing Social Policy, and Milton Kotelchuck and Raymond Levy from Harvard Medical School and The Fatherhood Project representing Health and Welfare. We are grateful for the Steering Committee's encouragement and intellectual guidance as we pulled together the Experts Meeting and this volume. We owe a special debt of gratitude to Milton Kotelchuck for working hand in hand with us in the final months of production.

We are enormously appreciative of the thought-provoking manuscripts the chapter authors have submitted. We also gratefully acknowledge their additional multi-faceted contributions as presenters at the Experts Meeting, as peer reviewers, and as advisers to the editors.

Finally, we would like to recognize Greg Dorchak's innumerable administrative and substantive contributions. Greg Dorchak led the logistical planning and implementation of the Experts Meeting and the operational production of the book with unerring professionalism and good humor. No chapter in this volume made it to press without his skillful text-editing. As a hardworking and engaged father, his enthusiasm for the subject has buoyed our collective work.

Finally, we thank our families who remind us every day of the joys and significance of loving fatherhood engagement.

\section{References}

Acker J (1990) Hierarchies, jobs, bodies: a theory of gendered organizations. Gend Soc 4 (2):139-158

Alio AP, Kornosky JL, Mbah AK, Marty PJ, Salihu HM (2010) The impact of paternal involvement on feto-infant morbidity among whites, blacks and Hispanics. Matern Child Health J 14 (5):735-741

Altintas E, Sullivan O (2017) Trends in fathers' contribution to housework and childcare under different welfare policy regimes. Soc Politics Int Stud Gend State Soc 24(1):81-108

Aumann K, Galinsky E, Matos K (2011) The new male mystique. Families and Work Institute, National Study of the Changing Workforce, Hillsborough

Bianchi SM (2011) Family change and time allocation in American families. Ann Am Acad Pol Soc Sci 638(1):21-44

Bueno X, Grau-Grau M (2021) Why is part-time unpaid parental leave (still) gendered? Narratives and strategies of couples in Spain. J Fam Issues 42(3):503-526

Bünning M (2015) What happens after the 'daddy months'? Fathers' involvement in paid work, childcare, and housework after taking parental leave in Germany. Eur Sociol Rev 31 (6):738-748

Cameron EE, Sedov ID, Tomfohr-Madsen LM (2016) Prevalence of paternal depression in pregnancy and the postpartum: an updated meta-analysis. J Affect Disord 206:189-203

Cano T, Perales F, Baxter J (2019) A matter of time: father involvement and child cognitive outcomes. J Marriage Fam 81(1):164-184

Eagle BW, Miles EW, Icenogle ML (1997) Interrole conflicts and the permeability of work and family domains: are there gender differences? J Vocat Behav 50(2):168-184 
Eggebeen DJ, Knoester C (2001) Does fatherhood matter for men? J Marriage Fam 63(2):381-393

Eggebeen DJ, Dew J, Knoester C (2010) Fatherhood and men's lives at middle age. J Fam Issues 31 (1):113-130

England P (2010) The gender revolution: uneven and stalled. Gend Soc 24(2):149-166

Esping-Andersen G (2009) The incomplete revolution: adapting to women's new roles. Policy Press, Cambridge

Gerson K (2010) The unfinished revolution: coming of age in a new era of gender, work, and family. Oxford University Press, Oxford

Goldin C, Mitchell J (2017) The new life cycle of women's employment: disappearing humps, sagging middles, expanding tops. J Econ Perspect 31(1):161-182

Goldscheider F, Bernhardt E, Lappegård T (2015) The gender revolution: a framework for understanding changing family and demographic behavior. Popul Dev Rev 41(2):207-239

Grau-Grau M (2017) Work-family enrichment experiences among working fathers: evidence from Catalonia. The University of Edinburgh, Edinburgh

Hearn J, Pringle K, Balkmar D (2018) Men, masculinities and social policy. In: Shaver S (ed) Handbook on gender and social policy. Edward Elgar, Northampton, pp 55-73

Higgins CA, Duxbury LE (1992) Work-family conflict: a comparison of dual-career and traditionalcareer men. J Organ Behav 13(4):389-411

Huerta MdC, Adema W, Baxter J, Han W-J, Lausten M, Lee RH, Waldfogel J (2013) Fathers' leave, fathers' involvement and child development: are they related? Evidence from four OECD countries. OECD social, employment and migration working paper no. 140. OECD, Paris

Kelly EL, Ammons SK, Chermack K, Moen P (2010) Gendered challenge, gendered response: confronting the ideal worker norm in a white-collar organization. Gend Soc 24(3):281-303

Lewis J (2001) The decline of the male breadwinner model: implications for work and care. Soc Polit Int Stud Gend State Soc 8(2):152-169

Livingston G, Parker K (2019) 8 facts about American dads. Pew Research Center, Fact Tank news in the numbers. https://www.pewresearch.org/fact-tank/2019/06/12/fathers-day-facts/. Accessed 31 Aug 2020

Mandel H, Semyonov M (2005) Family policies, wage structures, and gender gaps: sources of earnings inequality in 20 countries. Am Sociol Rev 70(6):949-967

Mayer M, Le Bourdais C (2019) Sharing parental leave among dual-earner couples in Canada: does reserved paternity leave make a difference? Popul Res Policy Rev 38(2):215-239

Moran J, Koslowski A (2019) Making use of work-family balance entitlements: how to support fathers with combining employment and caregiving. Community Work Fam 22(1):111-128

National Academies of Sciences, Engineering and Medicine, Board on Children, Youth, and Families, Division of Behavioral and Social Sciences and Education, National Academies ofSciences, Engineering, and Medicine (2016) In: Gadsden VL, Ford M, Breiner H (eds) Parenting matters: supporting parents of children ages 0-8. National Academies Press, Washington, DC

Nepomnyaschy L, Waldfogel J (2007) Paternity leave and fathers' involvement with their young children. Community Work Fam 10(4):427-453

Parasuraman S, Simmers CA (2001) Type of employment, work-family conflict and well-being: a comparative study. J Organ Behav 22(5):51-68

Petts RJ, Knoester C, Waldfogel J (2020) Fathers' paternity leave-taking and children's perceptions of father-child relationships in the United States. Sex Roles 82(3):73-88

Steen M, Downe S, Bamford N, Edozien L (2012) Not-patient and not-visitor: a metasynthesis fathers' encounters with pregnancy, birth and maternity care. Midwifery 28(4):422-431 
Tanquerel S, Grau-Grau M (2020) Unmasking work-family balance barriers and strategies among working fathers in the workplace. Organization 27(5):680-700. https://doi.org/10.1177/ 1350508419838692

Williams JC, Blair-Loy M, Berdahl JL (2013) Cultural schemas, social class, and the flexibility stigma. J Soc Issues 69(2):9-34

Wray D (2020) Paternity leave and fathers' responsibility: evidence from a natural experiment in Canada. J Marriage Fam 82(2):534-549

Yogman M, Garfield CF, Committee on Psychosocial Aspects of Child and Family Health (2016) Fathers' roles in the care and development of their children: the role of pediatricians. Pediatrics 138(1):e20161128

Open Access This chapter is licensed under the terms of the Creative Commons Attribution 4.0 International License (http://creativecommons.org/licenses/by/4.0/), which permits use, sharing, adaptation, distribution and reproduction in any medium or format, as long as you give appropriate credit to the original author(s) and the source, provide a link to the Creative Commons license and indicate if changes were made.

The images or other third party material in this chapter are included in the chapter's Creative Commons license, unless indicated otherwise in a credit line to the material. If material is not included in the chapter's Creative Commons license and your intended use is not permitted by statutory regulation or exceeds the permitted use, you will need to obtain permission directly from the copyright holder. 